\title{
Pelatihan Pembuatan Salad Buah Keju Sebagai Program Usaha Ekonomi Masyarakat Menengah ke Bawah
}

\author{
Ilham Nazaruddin*1, Ronald Mahmud², Yudi Umara ${ }^{3}$, Nur Isnaini Heni4 ${ }^{4}$, dan Dinda Wirly Dewani ${ }^{5}$ \\ 1,2,3Dosen STKIP Amal Bakti \\ 4,5Mahasiswa STKIP Amal Bakti \\ *e-mail: $\underline{\text { lhamnazaruddin08@gmail.com }}{ }^{1}$
}

\begin{abstract}
Abstrak
Dalam suatu pemasaran banyak sekali bentuk dan macam-macam aneka ragam makanan dari yang kecil hingga yang besar dan dari yang murah hingga sampai yang mahal. Masyarakat saat ini berusaha mengkonsumsi makanan sehat harus menjadi kebiasaaan agar kesehatan badan terjaga. Hal itu dilakukan dengan memilih makanan alami dan dalam kondisi segar, tanpa bahan pengawet. Salah satu makanan sehat yang aman dikonsumsi adalah salad, baik salad sayuran atau buah-buahan. Salad buah adalah makanan alternatif yang menyehatkan. Bahkan bisa mencegah dan mengobati beberapa jenis penyakit. Sayuran dan buah dalam salad kaya akan nutrisi, kandungan gizi, mengandung serat tinggi, juga mengandung berbagai vitamin dan mineral yang sangat berguna bagi kesehatan tubuh. Kita sering tak menyadari, semangkuk kecil salad buah dengan komposisi tepat, akan sangat berguna bagi 'kesegaran' tubuh kita. Salad memberikan kepada tubuh begitu banyak serat yang pada gilirannya akan menurunkan kolesterol dan mengurangi sembelit. Sejalan dengan masalah yang ditemukan maka pengabdian ini lebih memberikan suatu pengajaran bagaimana memanfaatkan buah-buahan untuk diolah menjadi salad yang nantinya dapat dikembangkan untuk menaikkan ekonomi masyarakatnya melalui penjualan dengan memanfaatkan e-commerce, tetapi sedikit pengetahuan yang dimiliki oleh masyarakat menengah ke bawah. Pola ajar dengan memberikan resep dan praktik lapangan pembuatan berbagai macam salad sayur dan pencampurannya dengan bahan lain seperti buah dan biji-bijian, serta mengenal jenis kemasan dan cara mengemas dengan baik lalu memasarkannya melalui e-commerce. Diharapkan masyarakat menegah ke bawah menjadi mengerti lebih lagi tentang bagaimana mengolah salad menjadi tahan lama serta dapat membuka peluang untuk menekuni bisnis makanan sehat.
\end{abstract}

Kata kunci: salad buah, ekonomi, kelas bawah

\section{Abstract}

In a marketing, there are many forms and various kinds of food from small to large and from cheap to expensive. Today's society tries to consume healthy food, it must become a habit so that the body's health is maintained. This is done by choosing natural foods and in fresh conditions, without preservatives. One of the healthy foods that are safe for consumption are salads, either vegetable or fruit salads. Fruit salad is a healthy alternative. It can even prevent and treat several types of diseases. Vegetables and fruit in salads are rich in nutrients, nutritional content, contain high fiber, also contain various vitamins and minerals that are very useful for body health. We often do not realize, a small bowl of fruit salad with the right composition, will be very useful for the 'freshness' of our body. Salad provides the body with so much fiber which in turn lowers cholesterol and reduces constipation. In line with the problems found, this service provides more of a teaching on how to use fruits to be processed into salads which can later be developed to increase the economy of the community through sales by utilizing e-commerce, but little knowledge is owned by the lower middle class. The teaching pattern is by providing recipes and field practice of making various kinds of vegetable salads and mixing them with other ingredients such as fruit and seeds, as well as knowing the types of packaging and how to pack them well and then marketing them through e-commerce. It is hoped that the middle and lower people will understand more about how to process salads to be durable and can open up opportunities to pursue the healthy food business.

Keywords: fruit salad, economy, lower class

\section{PENDAHULUAN}

Dalam suatu pemasaran banyak sekali bentuk dan macam-macam aneka ragam makanan dari yang kecil hingga yang besar dan dari yang murah hingga yang mahal. Dalam kebutuhan sehari-hari banyak sekali aktivitas yang dijalani oleh setiap orang. Dengan aktivitas 
yang semakin padat membuat banyak orang membutuhkan asupan makanan tambahan yang bermanfaat untuk kesehatan tubuh salah satunya adalah salad buah.

Salad buah merupakan sejenis makanan yang terdiri dari campuran buah- buahan, susu, mayones, keju dan lainnya. Salad buah dikategorikan sebagai makanan sehat karena dari komposisinya yang terdiri dari buah-buahan. Buah- buahan selain bisa dikonsumsi lebih fresh atau segar, juga mempunyai nilai gizi dan kandungan nutrisi yang kaya, lengkap dan berkesinambungan sepanjang musim di Indonesia. Selain bermanfaat untuk kesehatan tubuh, Salad buah merupakan salah satu jenis makanan sehat yang mengandung banyak serat dan vitamin dan harganya relatif murah dan terjangkau serta banyak diminati masyarakat. Salad buah merupakan salah satu jenis usaha yang sangat cocok untuk masyarakat menengah kebawah karena tidak harus mengeluarkan modal yang cukup besar dan cara pembuatanya yang tidak begitu sulit, dan menjanjikan omset yang besar, oleh karena itu salad buah sangat cocok untuk usaha masyarakat menengah kebawah terutama untuk pemasaran di kota Medan.

Salad Buah Keju (Salju) juga memiliki banyak manfaat bagi kesehatan tubuh. Orang dewasa atau remaja biasanya menyukai olahan buah dengan rasa khas seperti dibuat Salad Buah dibandingkan hanya dimakan seperti biasa saja. Bahan yang terkandung dalam Salad Buah ini sangat membantu proses pencernaan karena mengandung banyak serat yang didapat dari berbagai macam buah didalamnya. Untuk itu pembuatan usaha "Salju" ini bertujuan untuk memenuhi permintaan pembelian di kalangan remaja khususnya masyarakat pada umumnya.

Buah-buahan tersebut sempat menjadi terkenal karena mampu menurutkan berat badan dalam waktu yang cukup singkat. Oleh karena itu, banyak sekali orang-orang yang mengkonsumsi buah buahan tersebut untuk dijadikan salad buah karena selain menyegarkan dimulut dan tentunya kaya akan manfaat. Berbagai inovasi mengonsumsi buah didapatkan agar orang orang tertarik untuk mengonsumsi buah-buahan dan tidak bosan dengan cara mengkonsumsi buah buahan yang sering dilakukan sebelumnya. Perpaduan antara buah dan saus yang disatukan dalam satu tempat membuat makanan ini menjadi makanan popular di semua kalangan

\section{METODE}

Menurut Julianav[1], Salad buah adalah makanan alternatif yang menyehatkan, bahkan bisa mencegah dan mengobati beberapa jenis penyakit. Pemahaman dari Tjiptono \& Fandy [2] packaging termasuk metode yang berhubungan dengan pemrograman dan pembentukan tempat atau pelapis untuk suatu barang.

Kemasan termasuk aktivitas peletakan produk ke dalam wadah, tempat, isi, atau sejenisnya yang terbuat dari timah, kayu, kertas, gelas, besi, plastik, kain, karton.Kemasan bukan hanya terdiri atas pelayanan tetapi juga sebagai salesman dan pengantar kepercayaan, dimana suatu kemasan termasuk penglihatan akhir dari konsumen yang dapat dipercaya.

Menurut Kotler \& Keller [3]kemasan yang baik dapat membangun ekuitas merek dan mendorong penjualan. Menurut Majdah Zawawi[4], menyatakan bahwa e-commerce sangat mendukung pemasaran di bidang manufaktur untuk mendapatkan penghasilan karena dapat mengubah layanan. E-Commerce merupakan tindakan dukungan untuk memberikan informasi dan referensi tentang produk pertanian, pemasaran dan industri manufaktur terutama iklan di media sosial.

Dalam pelaksanaan kegiatan pengabdian ini, Tim membawa alat pencuci sayur dan buah, pisau, talenan, sendok, wadah besar. Pelaksanaan kegiatan pengabdian ini dilakukan mulai tanggal 12 April s.d. 10 Mei 2021. Adapun bahan yang digunakan adalah susu kental manis, mayones, keju, strawberry, jeruk, melon, papaya, buah naga, apel, pear, anggur, susu cair, dan jelly. Berikut ini cara pembuatan Salju Buah Keju adalah 1) Potong semua buah strawberry, melon, pepaya, buah naga, apel, dan pear, 2) Setelah itu buat saus dengan mencampur susu kental manis, yogurt mayones dan susu cair, lalu aduk rata, 3) Siapkan wadah, masukkan potongan buah strawberry, melon, pepaya buah naga, apel, pear, anggur dan jelly, 4) Tuang saus 
yogurt yang sudah dibuat diatasnya, 5) berikan potongan strawberry dan jeruk serta parutan keju, 6) "Salju" selesai dan siap di sajikan.

Pelaksanaan telah dilakukan dengan dua (2) tahapan, yaitu tahapan pertama, adalah melakukan pengajaran dan pelatihan dengan metode praktik langsung dan dilakukan secara Bersama, serta memberikan informasi-informasi yang sudah disiapkan dalam bentuk modul fotokopi. Memberikan pengajaran kepada masyarakat Kota Medan khususnya anggota PKK tentang cara membuat variasi salad buah keju. Berdasarkan permasalahan yang dihadapi oleh masyarakat Kota Medan, maka solusi yang dapat ditawarkan merupakan 1. Pengajaran tentang makanan salad buah keju serta penyimpanan dan kesegaran kemasan. 2. Memberikan pengetahuan mengenai kemasan dan label yang harus digunakan untuk buah dan makanan segar. 3. Mengajarkan penggunaan e-commerce dalam kepentingan pemasaran produk salad buah keju. Pengajaran cara pemasaran yang tepat menggunakan e-commerce dengan cara memilih beberapa orang dari peserta yang mampu atau bisa menggunakan perangkat komunikasi elektronik dengan baik, kemudian diajarkan secara Bersama dan orang yang terpilih telah menjadi mentor peserta yang lain. 4. Monitor telah dilakukan empat minggu dan sepuluh minggu setelah kegiatan pelatihan dengan hasil materi yang telah diberikan telah digunakan sesuai dengan hasil yang diharapkan. 5. Masyarakat dapat mempersiapkan diri untuk era pemasaran digital transformation 4.0.

Pengabdian masyarakat yang telah dilakukan ini lebih mengutamakan pada pengajaran bagaimana mengolah buah segar yang sudah berhasil ditanam menjadi suatu kreasi berbagai macam salad buah dan mencari faktor apa yang membuat konsumen membeli produk tersebut.

\section{HASIL DAN PEMBAHASAN}

Berikut ini hasil dan pembahasan dari Pelatihan Salad Buah Keju dibawah ini:

\section{a. Branding Produk}

"Salju" atau salad buah keju merupakan makanan sehat dan bergizi, rendah kalori dan halal, "Salju" juga bisa menjadi makanan solusi bagi masyarakat yang ingin merasakan sensasi berbeda memakan buah dengan cara dibuat menjadi salad, "Salju" juga mengandung banyak serat dan vitamin yang terkandung dari banyak buah-buahan didalamnya. Salad Buah Keju merupakan nama brand yang kami buat untuk usaha ini. Kenapa memberi nama salad buah keju karena kami mengambil dari produk yang kami jual yaitu salad buah yang diberi toping keju.

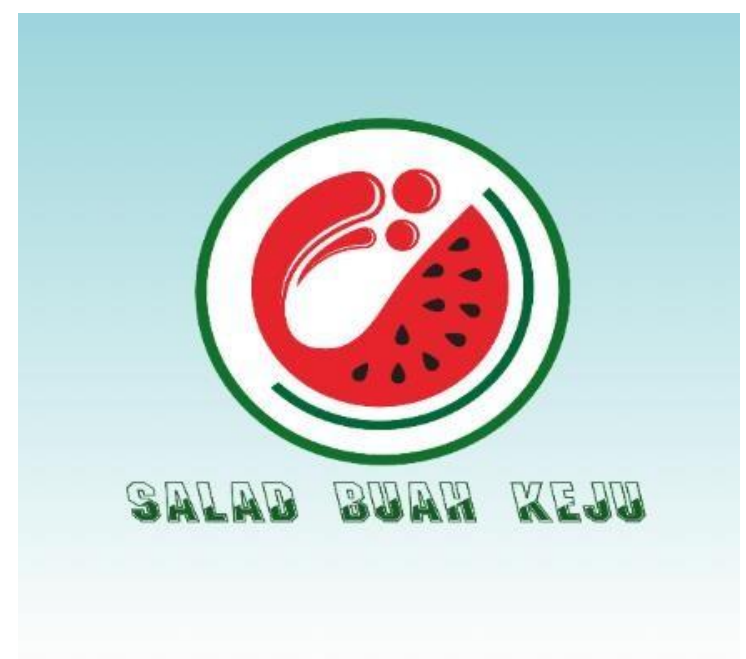

Gambar 1. Logo Salad Buah

Gambar semangka pada logo memiliki makna kesegaran dan juga karena produk yang dijual merupakan salad dan terdapat semangka yang menjadi salah satu bahannya, terbentuk di 
atas gradasi warna biru muda dan putih sebagai harapan agar produk ini memiliki harapan yang sama cerahnya dan tetap kuat serta jauh dari kata kegagalan.

\section{b. Teknik Digital Marketing}

Teknik digital marketing adalah salah satu cara untuk mempromosikan produk dan jasa menggunakan internet atau media sosial, kelebihannya untuk meningkatkan penjualan, meningkatkan branding serta membina hubungan dengan konsumen.

Kemajuan Teknologi Informasi (IT) merupakan sesuatu yang tidak bisa di hindari dalam kehidupan masa kini, karena kemajuan teknologi akan selalu berjalan seiring dengan kemajuan ilmu pengetahuan, pemanfaatan Teknologi Informasi (IT) dalam berbagai aktivitas salah satunya adalah melakukan pembelian produk melalui toko online seperti Lazada, Shopee, Tokopedia, dan banyak lainnya untuk mencari produk yang diinginkan.

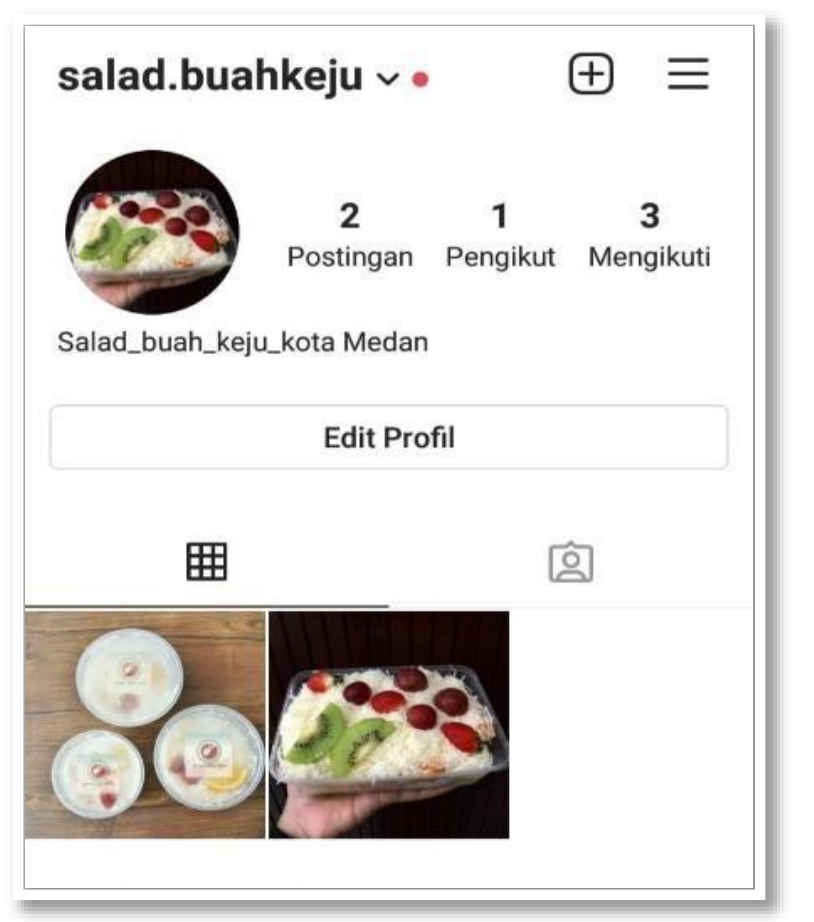

Gambar 2 . Instagram Salad Buah Keju

Perilaku tersebut tentu merupakan hal yang wajar mengingat keuntungan dari segi efisiensi waktu, tenaga, dan biaya yang dikeluarkan jauh lebih murah dibanding dengan cara konvensional, melihat kondisi tersebut tentu merupakan sebuah peluang besar bagi para pelaku Ekonomi khususnya produsen untuk memanfaatkan IT dan internet dalam proses transaksi atau jual beli barang.

Pada saat ini juga banyak E-Commerce dan media sosial seperti instagram, facebook, twitter, lazada, shopee, gojek dan grab. Gojek dan grab memiliki fitur layanan pesan antar makanan yang dapat memudahkan konsumen dalam membeli suatu produk. Maka dari itu "Salju" bertujuan memasukkan usahanya di media sosial Instagram dan E-Commerce gojek dan grab dan berharap di masa yang akan datang kami mampu membuat website dengan memanfaatkan Saerch Engine Marketing (SEM) fitur yang berguna untuk menempatkan website perusahaan atau bisnis berada di halaman pencari sekelas google. Hal tersebut bertujuan agar produk "Salju" dapat berkembang lebih maju dan dikenal banyak orang dan memudahkan customer dalam membeli "Salju” tanpa harus datang ke kedai.

\section{c. Packing Brand Produk}

Dalam usaha "Salju" ini kami menggunakan mika salad buah untuk membungkus produk dan di atasnya di tempelkan stiker logo "Salad Buah Keju". Menggunakan mika agar salad buah tetap terjaga kebersihannya, melindungi makanan agar tidah mudah rusak sehingga kualitas makanan tetap terjaga dan tentunya lebih praktis 


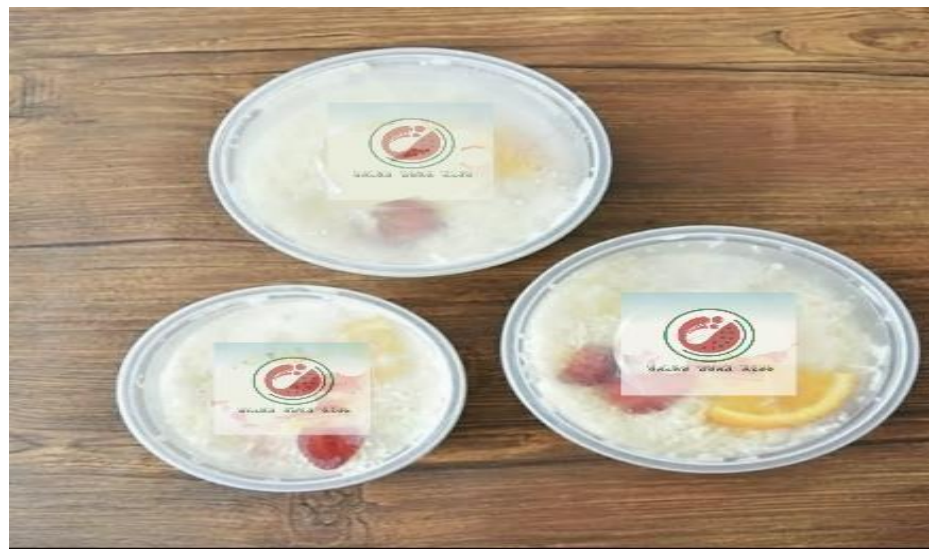

Gambar 3. Packing Salad Buah Keju

\section{KESIMPULAN}

Salju" atau salad buah keju merupakan makanan sehat dan bergizi, rendah kalori dan halal, "Salju" juga bisa menjadi makanan solusi bagi masyarakat yang ingin merasakan sensasi berbeda memakan buah dengan cara dibuat menjadi salad, "Salju" juga mengandung banyak serat dan vitamin yang terkandung dari banyak buah-buahan didalamnya..

Salad Buah Keju merupakan nama brand yang kami buat untuk usaha ini. Kenapa memberi nama salad buah keju karena kami mengambil dari produk yang kami jual yaitu salad buah yang diberi topping keju.

Usaha ini merupakan usaha menengah, kalangan manapun tahu dengan produk salad buah ini.Dalam usaha ini tidak memerlukan banyak orang karena usaha ini masih kecil-kecilan dan juga tidak membutuhkan orang yang memiliki keahlian khusus akan tetapi dibutuhkan sikap tekun, \& sabar.

\section{UCAPAN TERIMA KASIH}

Tim pelaksana pengabdian masyarakat mengucapkan terimakasih kepada Lembaga Pengabdian Kepada Masyarakat (LPkM) STKIP Amal Bakti yang telah memberikan dukungan pendanaan.

\section{DAFTAR PUSTAKA}

[1] Juliana, dkk, "Pelatihan Pembuatan Salad Sayur Hidroponik dan Cara Pemasaran yang Tepat dalam E-Commerce," Jurnal ABDIMAS BSI, vol. 3, no. 2, pp. 208-216, 2020.

[2] P. Kotler, and K. L. Keller, Manajemen Pemasaran Jilid 1 Edisi Ketiga belas, Jakarta, 2009.

[3] M. Zawawi and N. Ramli, "E-Commerce Sebagai Pendukung Pemasaran Perusahaan," Jurnal Ilmiah "Integritas," Vol. 2 No. May, pp. 31-48, 2016.

[4] Tjiptono and Fandy, Strategi Pemasaran, Edisi Kedua, Edisi I. Yogyakarta: Andi, 2010. 